\title{
ALEXANDRIA
}

Revista de Educação em Ciência e Tecnologia

\section{Quadros Analíticos para o Estudo e Desenvolvimento de Materiais Curriculares Educativos sobre Modelagem Matemática}

\author{
Analytical Tables for the Study and Development of Educative \\ Curriculum Materials on Mathematical Modeling
}

\author{
Airam da Silva Prado ${ }^{a}$; Andreia Maria Pereira de Oliveira ${ }^{b}$; Jonei Cerqueira Barbosab \\ a Universidade Federal da Bahia e Universidade Estadual de Feira de Santana, Feira de Santana, Brasil - \\ airamprado@gmail.com \\ b Faculdade de Educação, Universidade Federal da Bahia, Salvador, Brasil - ampo@ufba.br, jonei.cerqueira@ufba.br
}

Palavras-chave:

Modelagem matemática.

Materiais curriculares

educativos. Imagens da prática pedagógica.
Resumo: Este artigo, de cunho teórico, apresenta quadros analíticos para o estudo e desenvolvimento de Materiais Curriculares Educativos sobre Modelagem Matemática (MCEMM). Os quadros analíticos foram construídos a partir de uma pesquisa de mestrado e estão orientados sob as lentes da Teoria dos Códigos de Basil Bernstein. A análise aponta que MCEMM podem sugerir variações do controle na relação pedagógica, estando o controle centrado no professor e, outras vezes, compartilhado com estudantes. Além disso, os MCEMM podem indicar formas de organizar as possibilidades para o esbatimento do grau de isolamento nas relações entre discursos assim como nas relações entre espaços.

Abstract: This theoretical paper presents analytical frameworks for the study and development of Mathematical Modelling Educational Curriculum Materials (MMECM). The analytical frameworks were constructed from a master's research and are oriented under the lens of Basil Bernstein's Code Theory. The analysis indicates that MMECM can suggest variations of control in the pedagogical relation, being the control centered in the teacher and, at other times, shared with students. In addition, MMECM may indicate ways of organizing possibilities for blurring the degree of isolation in the relationships between discourses as well as in the relationships between spaces. 


\section{Introdução}

Uma das propostas de inovações pedagógicas ${ }^{1}$ discutidas na Educação Matemática tem sido a modelagem matemática (BARBOSA, 2009; BIEMBENGUT, 2014; ALMEIDA; ZANIN, 2016). De modo geral, nesta proposta, estudantes e professores lidam com problemas externos à matemática, os quais são provenientes de situações do dia-a-dia ou de outras áreas das Ciências (BARBOSA, 2009).

$\mathrm{Na}$ literatura, estas situações têm sido apresentadas por pesquisadores da Educação Matemática como tendo potencial para motivar a aprendizagem de conteúdos curriculares (BIEMBENGUT, 2014); possibilitar que estudantes reflitam sobre o papel da matemática na sociedade (BARBOSA, 2009); e suscitar a ação, atuação e participação de estudantes na sociedade (JACOBINI, 2007).

As práticas pedagógicas ${ }^{2}$ no ambiente de modelagem ${ }^{3}$ podem ser descritas por características próprias. Como argumentado em Skovsmose (2000), os problemas de modelagem, ao envolverem dados da vida real, oferecem uma diferente condição de comunicação entre professor e estudantes, uma vez que faz sentido questionar e suplementar as informações dadas pelas situações, fatos estes, que estabelecem formas específicas para a relação social entre professor e estudantes. Por exemplo, as aulas no ambiente de modelagem requerem que professores estabeleçam relações entre conhecimentos formais da disciplina matemática e conhecimentos provenientes dos contextos, dos quais os dados foram extraídos, sendo, portanto, uma característica desse ambiente que se estabeleça relações entre discursos da matemática escolar e discursos extraescolares. Uma consequência disto, é que tanto professores quanto estudantes têm seus papéis redefinidos se compararmos às práticas ditas tradicionais.

No entanto, são poucas as iniciativas de desenvolvimento de materiais curriculares que apoiam a implementação da modelagem no contexto escolar. Por exemplo, Ikeda (2007), ao realizar uma pesquisa sobre a inserção da modelagem matemática nas práticas pedagógicas escolares em oito países, incluindo o Brasil, destacou como um dos principais problemas para essa inserção, a falta de materiais curriculares adequados e compatíveis com os programas curriculares dos países.

O termo material curricular é entendido como todo e qualquer recurso utilizado para apoiar a apresentação e a interação com o currículo formal, oficial, prescrito e explícito. Inclue livros didáticos e outros materiais impressos, tais como tarefas para estudantes,

\footnotetext{
1 As inovações pedagógicas são entendidas como as práticas pedagógicas que rompem ou ultrapassam o esquema clássico de exposição-escuta-memorização-repetição (aula tradicional), que tem como questão central o programa (FERNANDES; BLENGINI, 2012).

${ }^{2} \mathrm{O}$ termo prática pedagógica, por enquanto, será tomado de maneira intuitiva, ao longo do artigo, definiremos de maneira mais precisa.

${ }^{3}$ Por vezes, usaremos a palavra modelagem, para nos referir a modelagem matemática na Educação Matemática. 
materiais manipulativos e documentos utilizados para apoiar o planejamento de aulas de professores (BROWN, 2009). Além disso, consideramos que materiais curriculares podem tomar uma variedade de formas, inclusive recursos não impressos, como textos disponíveis onlines, blogs, softwares, entre outros.

No Brasil, um estudo realizado por Siqueira (2014), o qual teve como objetivo analisar livros didáticos aprovados pelo Programa Nacional do Livro Didático (PNLD) para o triênio (2012-2013-2014), verificou que não existem tarefas explícitas de modelagem matemática. Em nenhuma das obras analisadas foram encontradas possibilidades de modalidades pedagógicas diferenciadas das práticas expositivas tradicionais. Nos manuais pedagógicos (manuais para professores) que acompanham estes livros, são mencionados a importância da utilização de estratégias de ensino, que favoreçam a aprendizagem, diversas vezes, no entanto, não ficam evidentes estas estratégias na apresentação da obra.

Silva et al. (2009) analisaram se tarefas presentes em um dos livros aprovados pelo Programa Nacional do Livro Didático para o Ensino Médio (PNLEM/2009), oportunizavam o trabalho com modelagem matemática na perspectiva sociocrítica ${ }^{4}$, ao observar se as tarefas propostas apresentavam as seguintes características: (a) aborda tema do cotidiano/realidade que possa ser de interesse de estudantes; situação-problema que permite problematização/contextualização; (b) permite/incentiva a pesquisa/busca de informações fora do livro-texto, além das apresentadas nos capítulos; (c) apresenta mais de uma questão a ser respondida e/ou permite o levantamento de mais questões, matemáticas ou não, além das apresentadas no texto/tarefa; (d) apresenta tema/questão que pode ser resolvida/discutida em grupo ou com outros colegas; (e) as questões apresentadas/levantadas podem ser resolvidas, utilizando conhecimentos que estudantes já possuem ou constituem condição inicial para professores introduzirem um novo conteúdo e dar margem para discussão/verificação/validação/análise das respostas obtidas.

A partir da análise, Silva et al. (2009), destacaram, em todo o livro, 6 (seis) tarefas que satisfazem todas as características mencionadas e mais uma que satisfazem as características (a) e (b). No entanto, argumentaram que o livro não sinaliza explicitamente nas orientações aos professores sobre modelagem matemática e não oferece apoio ao professor referente as tarefas em específico. Assim, concluem que, apesar do livro apresentar tarefas com essas características, as quais diferenciam de uma tarefa tradicional de resolução de problemas, visto que elas incorporam algumas características que impulsionam tanto estudantes quanto professores a mudarem de conduta com relação à aula tradicional, o trabalho com modelagem

\footnotetext{
${ }^{4}$ Kaiser e Sriraman (2006) distinguem 5 (cinco) perspectivas da inserção da modelagem matemática no currículo: realística, epistemológica, educacional, sociocrítica e contextual. A perspectiva sociocrítica coloca foco sobre o papel dos modelos matemáticos na sociedade (BARBOSA, 2006).
} 
matemática está intimamente relacionado a condução dada pelo(a) professor(a) à aula, ou seja, ele/ela tem grande participação no direcionamento da tarefa para o êxito da proposta.

Assim, este artigo, de cunho teórico, visa contribuir com o campo investigativo em modelagem matemática ao oferecer quadros analíticos sobre como práticas pedagógicas em ambientes de modelagem matemática podem ser representadas em materiais curriculares educativos. Por enquanto, entenderemos materiais curriculares educativos como aqueles elaborados com a finalidade de apoiar a aprendizagem de professores, para além da aprendizagem de estudantes.

\section{Materiais curriculares educativos: explorando outras potencialidades dos materiais curriculares}

Para a discussão apresentada neste artigo, estamos incluindo para materiais curriculares: diretrizes/parâmetros curriculares (especificam, geralmente, o que se espera que estudantes aprendam); programas curriculares (planos de ensino anual, planos de unidades ou planos de aula); livros (incluindo livros didáticos e paradidáticos, livros do professor, livro dos estudantes, impressos ou digitais); materiais criados pelos professores e/ou instituições de ensino (tarefas, atividades, sequências didáticas e etc.) e outros recursos manipuláveis e tecnológicos (jogos, calculadoras, computadores, softwares e etc.), além de publicações profissionais que se concentram no currículo. Destes, certamente, os livros didáticos são os que estão mais presentes nas rotinas escolares.

Segundo Collopy (2003), uma justificativa para isto, é seu baixo custo, aliado a possibilidade de atender as práticas pedagógicas em larga escala. Para além disso, uma potencialidade pouco explorada dos materiais curriculares é que estes podem oferecer apoio aos professores em relação às novas abordagens pedagógicas, caso sejam construídos com essa intenção (COLLOPY, 2003). Assim, apoiados na prerrogativa de que os materiais podem servir de apoio às práticas pedagógicas, estudos têm sugerido características que podem potencializá-los a partir dos resultados de investigações educacionais (DAVIS; KRAJCIK, 2005, REMILLARD, 2005).

Davis e Krajcik (2005), por exemplo, sugerem que materiais curriculares podem trazer descrições de sua utilização em sala de aula, como narrativas, relatos de episódios, vídeos de aulas, dúvidas dos estudantes sobre uma tarefa específica, etc. Materiais que apresentam tais características têm sido denominados, na literatura, por Materiais Curriculares Educativos $(\mathrm{MCE})^{5}$. O argumento apresentado pelos elaboradores deste tipo de material curricular é que o professor pode analisar como determinada tarefa foi utilizada em um contexto específico,

\footnotetext{
${ }^{5}$ A partir daqui, quando utilizarmos o temo "material" ou "material curricular" estamos nos referindo aos que carregam características de educativos.
} 
levantando hipóteses sobre como poderia ser no seu espaço de trabalho, facilitando, assim, o contato de professores com mudanças indicadas nas propostas educacionais (DAVIS; KRAJCIK, 2005; REMILLARD, 2005).

De fato, ao apresentar o desenvolvimento de uma tarefa por meio de narrativas e vídeos das aulas, além de outros suportes, como registros de estudantes e comentários de professores, o material acaba por expressar alguns indícios da relação entre professores e estudantes no contexto escolar. Por exemplo, eles podem explicitamente ajudar professores a antecipar e interpretar as conjecturas de estudantes, incluindo ideias alternativas, possíveis dúvidas, perguntas e etc. Materiais curriculares educativos também fornecem sugestões de como eles podem ser transformados para melhor alinhar com conhecimentos prévios e experiências de estudantes. A intenção é que os MCE possibilitem que professores sejam inspirados a partir de situações de sala de aula.

Portanto, o papel crucial do material curricular educativo é possibilitar aos professores uma possível abordagem da prática pedagógica quando professores e estudantes se envolvem em torno de uma tarefa no contexto de sala de aula. Tal potencialidade dos materiais curriculares educativos pode trazer contribuições no que se refere à formação de professores em relação às inovações pedagógicas, já que muitas das vezes, tais inovações pressupõem formas de trabalho e de organização da prática pedagógica diferentes das quais professores estão familiarizados a desenvolver em aulas.

Neste sentido, para além de se objetivar a aprendizagem de estudantes, os materiais curriculares educativos também podem oferecer apoio aos professores na reorganização de práticas pedagógicas, de acordo com as novas formas de trabalho propostas pelas inovações educacionais. E, sendo assim, a palavra educativo faz referência aos professores (REMILLARD, 2005; DAVIS; KRAJCIK, 2005).

Prado et al. $(2014,2016)$ analisaram materiais curriculares com características de educativos, os quais foram desenvolvidos por um Grupo Colaborativo ${ }^{6}$. A análise foi mediada pelos conceitos da Teoria dos Códigos de Basil Bernstein (2000). Na seção, a seguir, resgatamos alguns resultados destes dois estudos a fim de construir um quadro analítico sobre como as práticas pedagógicas em ambientes de modelagem matemática podem ser representadas nos materiais curriculares educativos.

\footnotetext{
${ }^{6}$ O GCMM era um projeto de extensão universitária (Resolução UEFS/CONSEPE No. 120/2007) da Universidade Estadual de Feira de Santana (UEFS), que congregava professores da educação básica, formadores da educação superior, pesquisadores em modelagem e graduandos da Licenciatura em Matemática. O GCMM esteve certificado enquanto projeto de extensão pela UEFS até maio de 2015. Atualmente, o grupo continua se reunindo nas escolas dos professores participantes, sem vínculo institucional com a UEFS. Os MCE produzidos pelo grupo podem ser acessados pelo link: http://colaboracaoprofessores.blogspot.com.br.
} 


\section{Análise de materiais curriculares educativos numa perspectiva sociológica bernsteiniana}

Ao trazer descrições das aulas por meio de vídeos, narrativas, questões de estudantes, e etc., contando detalhes da implementação de determinada tarefa, os materiais curriculares educativos podem explicitar algumas características das interações entre professores e estudantes e das possibilidades de organização do espaço de sala de aula, assim como os modos pelos quais os discursos das disciplinas escolares e os discursos extraescolares atrelados a esta prática pedagógica podem ser organizados e valorizados por seus participantes. De certa maneira, tais materiais podem carregar determinadas características de uma prática pedagógica.

Segundo Bernstein (2000), a caracterização de qualquer prática pedagógica deve contemplar três domínios de análise: relações específicas de poder e controle entre sujeitos, relações específicas de poder entre espaços e relações específicas de poder entre discursos. Este autor utiliza o termo prática pedagógica para se referir ao lócus das relações sociais entre transmissores e adquirentes ${ }^{7}$ para produção e reprodução cultural.

De acordo com Bernstein (2000), os princípios de controle que operam em um determinado agrupamento social e regulam a comunicação dentro de um determinado contexto (escolas, igrejas, famílias, etc.) constituem o enquadramento. Este regula quem controla os princípios de comunicação: regras de seleção (o que se comunica); regras de sequenciamento (em que ordem será comunicado); regras de ritmagem (qual o ritmo da comunicação) e regras hierárquicas (quais as formas da comunicação). Assim, no contexto da escola, no âmbito das relações sociais entre professores e estudantes, o enquadramento é dito forte quando o(a) professor(a) controla os princípios de comunicação; e o enquadramento é enfraquecido quando estudantes têm algum controle sobre os princípios de comunicação.

Bernstein (2000) também desenvolveu o conceito de classificação, o qual se refere às relações entre categorias (sejam elas categorias de sujeitos, discursos, agências, e etc.). Por exemplo, em qualquer agrupamento social podem ser observadas diferentes categorias de sujeitos - pais, filhos, irmãos, grupos etários, geracionais ou de gênero - que mantêm entre si um distanciamento, ou seja, uma classificação. Assim, no contexto da escola, no âmbito das relações sociais entre professores e estudantes, recorrendo ao conceito de classificação, dado o papel institucional do professor, ou seja, seu estatuto social na relação pedagógica, admitese que a classificação é forte, correspondendo a variação em maior ou em menor intensidade.

No entanto, na relação estudante-estudante, a classificação pode variar de muito forte até muito fraca. Por exemplo, considera-se uma classificação fraca quando se esbatem as

\footnotetext{
7 A escolha da palavra adquirente, segundo Bernstein (2000), aponta para a atuação ativa e não para a passividade. Assim, o uso desta palavra, neste artigo, identifica indivíduos com papéis sociais diferentes e não tem relação com a ideia de que o professor é transmissor e detentor do conhecimento, enquanto que o estudante é um sujeito passivo nesse processo.
} 
fronteiras entre estudantes de diferentes grupos sociais (quanto ao gênero, raça ou aproveitamento escolar), enquanto que se considera uma classificação forte quando se verificam hierarquias entre os próprios estudantes (MORAIS; NEVES, 2003).

Segundo Bernstein (1990), é no contexto comunicativo ${ }^{8}$ que a aquisição dos códigos ${ }^{9}$ se processa e é, portanto, por meio da classificação e do enquadramento, que são veiculados a distribuição de poder e o princípio de controle. Assim, é por meio das práticas pedagógicas que o código é adquirido, e para isto, elas constituem, relacionam e regulam as possibilidades de dois princípios de comunicação: o interacional e o localizacional (BERNSTEIN, 1990). O princípio interacional regula a seleção, a sequência e a ritmo da comunicação, seja ela oral, escrita ou visual, bem como a posição, a postura e os comportamentos dos comunicantes. Por outro lado, o princípio localizacional regula a localização física e a forma da sua realização, isto é, a variedade de objetos e seus atributos, e a sua relação mútua com o espaço no qual eles são constituídos.

A fim de operacionalizar esses dois conceitos, Morais e Neves (2003) adaptaram o modelo de Bernstein, distribuindo tais princípios em duas dimensões da prática pedagógica: a dimensão interacional e a dimensão estrutural. A dimensão interacional do contexto da sala de aula, e da prática pedagógica que nela se realiza, é dada pelas relações de controle entre sujeitos (por exemplo, professor(a)-estudante, estudante-estudante), enquanto que a dimensão estrutural é dada pelas relações de poder entre espaços, discursos e sujeitos (MORAIS; NEVES, 2003).

Para analisar a dimensão interacional, é utilizado o conceito de enquadramento e para a dimensão estrutural é utilizado o conceito de classificação. Assim, no âmbito da sala de aula e considerando a dimensão interacional, o conceito de enquadramento refere-se às relações de comunicação dentro de um contexto comunicativo (por exemplo, considerando a escola, a relação entre professores e estudantes e entre estudantes). Em relação à dimensão estrutural da prática pedagógica, o conceito de classificação refere-se ao grau de manutenção de fronteiras entre categorias (por exemplo, entre professores e estudantes, entre espaços utilizados pelos sujeitos, entre os diferentes discursos das disciplinas escolares, entre escola e comunidade, etc.).

Prado et al. (2014), ao analisar materiais curriculares educativos sobre modelagem matemática, utilizando o conceito enquadramento, proposto por Bernstein (2000), observaram que os textos ${ }^{10}$ destes materiais caracterizavam uma prática pedagógica, na qual o controle

\footnotetext{
${ }^{8}$ Bernstein $(1990,2000)$ utiliza a expressão contexto comunicativo para se referir ao contexto no qual a prática pedagógica acontece (como exemplo, escola, família, igreja, trabalho, etc.).

${ }^{9} \mathrm{O}$ código é um princípio regulador, tacitamente adquirido, que seleciona e integra significados relevantes (significados), a forma da sua realização (realizações) e os contextos evocadores (contextos) (BERNSTEIN, 2000).

${ }^{10}$ Texto é entendido como qualquer representação pedagógica escrita e visual (BERNSTEIN, 1990).
} 
estava, por vezes, centrado no(a) professor(a), enquanto que em outros momentos esse controle era compartilhado com estudantes. Isto se justifica pelo fato de que nos textos analisados, foi sugerido que o (a) professor (a) selecionasse os temas e os problemas ${ }^{11}$, assim como um conjunto de informações quantitativas e qualitativas para a prática pedagógica de modelagem matemática, o que caracteriza, um forte controle sobre as regras de seleção. No entanto, há explícita indicação sobre a valorização aos textos orais dos estudantes nestes materiais, e de aspectos do cotidiano nos argumentos dos mesmos, e além disso, todas as tarefas propostas são indicadas para que sejam resolvidas nas aulas, o que caracteriza um enfraquecimento do controle para as regras de ritmagem.

Neste sentido, Prado et al. (2014) concluem que o controle na comunicação entre professores e estudantes constituiu o que foi denominado de imagens de deslocamentos. Uma imagem de deslocamento foi definida como aquela capaz de criar, condicionar e organizar as possibilidades para a variação do controle na comunicação nas relações entre sujeitos. Tal imagem foi caracterizada pela intensa variação entre um enquadramento forte, no qual as práticas pedagógicas são caracterizadas pelo intenso controle por parte dos professores, e valores mais fracos de enquadramentos, nos quais as práticas pedagógicas podem ser descritas como um compartilhar do controle entre professores e estudantes.

No Quadro 1, a seguir, a coluna 1 indica as regras da dimensão interacional. A coluna 2 sintetiza questões que podem orientar a análise de textos de materiais curriculares educativos de modelagem matemática. Essas questões foram constituídas a partir de características já postas na literatura sobre modelagem matemática, em especial as evidenciadas nos trabalhos de Silva et al. (2009) relacionando-as a dimensão interacional da prática pedagógica. As colunas 3 e 4 apresentam dois extremos de variações no controle para cada uma das regras. Apesar de entendermos que entre os extremos fortes e fracos podem haver gradações, configurando, assim, outras possibilidades na relação, entendemos que as possibilidades descritas são suficientes para explicarmos o conceito de imagens de deslocamentos. Assim, podemos dizer que um texto ou uma prática pedagógica é caracterizada por imagens de deslocamentos quando eles apresentam variações entre controles fortes e fracos para diferentes regras.

Um resultado importante apresentado por Prado et al. (2014), a partir da análise, é que, o enfraquecimento das regras na prática pedagógica sugerido pelos elaboradores, o qual foi identificado ao nível das regras hierárquicas e de ritmagem, não foram identificadas no material curricular dirigido aos estudantes (tarefa do estudante) e sim, foram inferidas a partir dos vídeos, narrativas e soluções dos estudantes ou seja, elementos que compõem o material

11 Todos os materiais analisados neste estudo partiam de tarefas de modelagem matemática do caso 1 (BARBOSA, 2009). No caso 1, professores selecionam o tema, os dados qualitativos e quantitativos e cabe aos estudantes juntamente com o(a) professor(a) resolver o problema. 
curricular que é direcionado aos professores, os quais são característicos de um material curricular educativo. Além disso, os materiais curriculares educativos, ao sustentarem por meio das imagens da prática pedagógica uma gama potencial de textos legítimos, criam, como consequência, textos não legítimos a determinado contexto.

É neste sentido que o estudo de Prado et al. (2014) sugere outra imagem da dimensão interacional da prática pedagógica em materiais curriculares educativos. Em direção contrária às imagens de deslocamentos, as imagens de acumulação são aquelas que criam, condicionam e organizam as possibilidades para a manutenção do controle nas relações entre sujeitos. As imagens de acumulação podem ser capazes de sugerir práticas pedagógicas totalmente abertas, nas quais o adquirente participa de todas as escolhas e decisões do processo de aprendizagem (as imagens descritas na coluna 4); ou, em outro extremo, nas quais o adquirente é totalmente alheio a estas escolhas e decisões (as imagens descritas na coluna 3).

Em Prado et al. (2016), os textos dos materiais curriculares educativos sobre modelagem matemática foram analisados em relação às categorias de discursos e espaços. Os autores observaram que estes materiais caracterizavam uma prática pedagógica, na qual há um esbatimento dos limites/partições e das hierarquias entre as categorias analisadas, sejam elas, categorias de discursos (interdisciplinares, intradisciplinares, escolares e extraescolares) e espaços (espaço dos professores e espaços dos estudantes, espaços dos diferentes estudantes). Por exemplo, ao analisar as relações entre os discursos intradisciplinares, os autores evidenciaram que os conteúdos específicos da disciplina Matemática, nos textos dos materiais, não foram estratificados apenas em termos de uma lógica da matemática escolar, apresentando alguma relação hierárquica entre eles, mas em termos dos conteúdos necessários para entender/resolver o problema proposto, uma vez que estava estabelecido alguma relação entre conteúdos e as principais ideias chaves do problema proposto.

Portanto, a seleção e organização de conteúdos levam em conta sua relevância para a resolução do problema, não tendo como critérios de seleção e organização apenas a lógica interna da matemática. Além disso, Prado et al. (2016) identificaram que os textos sugerem forte referência ao discurso não acadêmico e um apelo à relação entre os dois tipos de discursos (escolares e extraescolares) já que ambos os discursos são esperados nas soluções dos estudantes. Os autores sugerem também que o texto explicitava um enfraquecimento do isolamento entre os espaços do(a) professor(a) e dos estudantes, o que sugere uma prática na qual os espaços são utilizados por todos, independentemente de sua posição social, podendo a relação entre espaços, nos textos dos materiais, serem caracterizadas por uma classificação muito fraca.

Esse esbatimento dos limites observado no material curricular educativo constituiu o que eles denominaram de imagem flexibilizadora, sendo definida como aquela capaz de criar, 
condicionar e organizar as possibilidades para o esbatimento do grau de isolamento nas relações discursivas (relações entre discursos), assim como nas relações espaciais (relações entre espaços).

Ao evidenciarmos que os materiais curriculares educativos sobre modelagem matemática comportam uma imagem flexibilizadora da dimensão estrutural da prática pedagógica em modelagem matemática, significa dizer que seus textos sugerem que os discursos nessa prática tendem à integração e que há uma tendência a não especialização dos espaços na organização desse ambiente de aprendizagem. Ou seja, o discurso da matemática escolar não deve ser o dominante em um ambiente de modelagem matemática, mas ele deve estar integrado aos discursos de outras disciplinas escolares e/ou discursos extraescolares. Tal princípio é coerente com as discussões postas na literatura em modelagem matemática, especialmente, no âmbito da perspectiva sociocrítica.

Quadro 1: Síntese das características da dimensão interacional em Materiais Curriculares Educativos sobre Modelagem Matemática

\begin{tabular}{|c|c|c|c|}
\hline Regras & Questões & O controle é fortalecido & O controle é enfraquecido \\
\hline Seleção & $\begin{array}{l}\text { (1) Qual, e como é } \\
\text { selecionado o tema da } \\
\text { tarefa? (2) Qual, e como é } \\
\text { selecionado o problema? (3) } \\
\text { Quais, e como é selecionado } \\
\text { as informações quantitativas } \\
\text { e qualitativas? (4) Quais, e } \\
\text { como é selecionado os } \\
\text { conteúdos? (5) Quais, e } \\
\text { como é selecionado os } \\
\text { procedimentos? (6) Quais, e } \\
\text { como são selecionas as } \\
\text { estratégias de resolução? }\end{array}$ & $\begin{array}{l}\text { Quando o(a) professor(a) } \\
\text { seleciona todos ou a maioria } \\
\text { dos itens da prática } \\
\text { pedagógica no ambiente de } \\
\text { modelagem. }\end{array}$ & $\begin{array}{l}\text { Quando o(a) professor(a) e } \\
\text { estudantes partilham a } \\
\text { seleção de todos ou a } \\
\text { maioria dos itens da prática } \\
\text { pedagógica no ambiente de } \\
\text { modelagem. }\end{array}$ \\
\hline Sequenciamento & $\begin{array}{l}\text { (7) A prática é } \\
\text { explicitamente sequenciada } \\
\text { em termos dos conteúdos } \\
\text { matemáticos } \\
\text { progressiva em termos da } \\
\text { dificuldade dos conteúdos) } \\
\text { ou procedimentos } \\
\text { (sequência de passos ou } \\
\text { procedimentos) } \\
\text { matemáticos? }\end{array}$ & 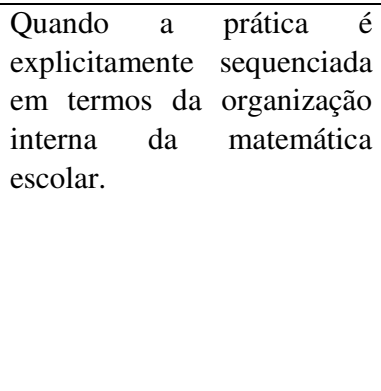 & $\begin{array}{l}\text { Quando a prática é } \\
\text { explicitamente sequenciada } \\
\text { em termos das necessidades } \\
\text { de aprendizagens dos } \\
\text { estudantes ou das estratégias } \\
\text { de resoluções dos mesmos. }\end{array}$ \\
\hline Ritmagem & $\begin{array}{l}\text { (8) Há valorização sobre a } \\
\text { fala/textos orais dos } \\
\text { participantes? (9) Há } \\
\text { valorização dos aspectos do } \\
\text { cotidiano nos argumentos } \\
\text { dos participantes? (10) As } \\
\text { tarefas são realizadas em } \\
\text { classe/extraclasse? (11) Há } \\
\text { condicionantes em relação } \\
\text { aos conteúdos/temas à } \\
\text { relação idade/série? }\end{array}$ & $\begin{array}{l}\text { Os conteúdos estão } \\
\text { organizados de acordo a } \\
\text { relação idade/série. } \\
\text { Organizados em unidades, } \\
\text { sendo que a tarefa não } \\
\text { ultrpassa, nem requisita } \\
\text { conteúdos não estabelecidos } \\
\text { para aquela unidade de } \\
\text { ensino. Não há valorização } \\
\text { aos textos orais dos } \\
\text { estudantes, nem de aspectos } \\
\text { do cotidiano. As tarefas são } \\
\text { resolvidas em casa. }\end{array}$ & $\begin{array}{l}\text { Os conteúdos não } \\
\text { estabelecem relação } \\
\text { idade/série. Há a inserção de } \\
\text { conteúdos não estabelecidos } \\
\text { para aquela unidade de } \\
\text { ensino. Há valorização aos } \\
\text { textos orais dos estudantes, } \\
\text { de aspectos do cotidiano, e } \\
\text { as tarefas são resolvidas na } \\
\text { classe. }\end{array}$ \\
\hline Criteriais & $\begin{array}{lr}\text { (12) } & \text { Há } \\
\text { descrição/explicitação sobre } \\
\text { o que estudantes devem } \\
\text { interpretar? (13) Há }\end{array}$ & $\begin{array}{l}\begin{array}{l}\text { Temas, dados e problemas } \\
\text { descritos }\end{array} \\
\text { são } \\
\text { minunciosamente, sendo } \\
\text { explícito o que estudantes } \\
\text { devem interpretar. É }\end{array}$ & $\begin{array}{l}\text { Os critérios para o tema, } \\
\text { dados e problema são } \\
\text { selecionados e discutidos } \\
\text { juntamente com estudantes. }\end{array}$ \\
\hline
\end{tabular}




\begin{tabular}{|c|c|c|c|}
\hline & $\begin{array}{l}\text { descrição/explicitação sobre } \\
\text { os critérios para soluções? } \\
\text { (14) } \\
\text { descrição/explicitação sobre } \\
\text { as hipóteses que estudantes } \\
\text { devem levar em } \\
\text { consideração para resolver o } \\
\text { problema? }\end{array}$ & $\begin{array}{l}\text { previsto uma única solução } \\
\text { ou soluções similares. }\end{array}$ & $\begin{array}{l}\text { Assim como, os critérios de } \\
\text { solução. Logo, espera-se } \\
\text { diferentes soluções. }\end{array}$ \\
\hline Hierárquicas & $\begin{array}{l}\text { (15) Existe } \text { espaço para } \\
\text { negociação? (16) Existem } \\
\text { posições hierárquicas } \\
\text { definidas entre estudantes } \\
\text { (líderes de equipe, por } \\
\text { exemplo) definidos pelo(a) } \\
\text { professor(a) ou pelos } \\
\text { próprios estudantes? (17) } \\
\text { São disponibilizadas iguais } \\
\text { possibilidades } \\
\text { participação para todos } \\
\text { estudantes? (18) Existe } \\
\text { algum condicionante para a } \\
\text { participação? }\end{array}$ & $\begin{array}{l}\text { Não existe espaço para } \\
\text { negociação e reinvidicações } \\
\text { ou questionamentos de } \\
\text { estudantes em relação a } \\
\text { tarefa. As tarefas são feitas } \\
\text { individalmente. Alguns } \\
\text { estudantes são sorteados } \\
\text { para apresentar suas } \\
\text { soluções. }\end{array}$ & \begin{tabular}{llr} 
Existe & espaço & para \\
negociação entre professores \\
e estudantes, podendo-se \\
alterar a & tarefa. & As \\
discussões e & soluções & são \\
feitas em & grupos & sem \\
posições & \multicolumn{2}{c}{ hierárquicas } \\
definidas. A & todos(as) \\
estudantes & & são \\
disponibilizadas & iguais \\
possibilidades & & de \\
participação. & &
\end{tabular} \\
\hline
\end{tabular}

Fonte: Os autores.

A perspectiva sociocrítica, segundo Kaiser e Sriraman (2006), está direcionada para o estudo de situações-problema que privilegiam a compreensão crítica do mundo, bem como o papel do indivíduo na sociedade. As tarefas de modelagem, nesta perspectiva, podem ser conduzidas de forma que, por meio da matemática, o estudante identifique outras formas de ver o mundo em que vive, ampliando seu espectro de possibilidades de ação e interação na sociedade.

Orey e Rosa (2007) sustentam que a modelagem oportuniza aos estudantes a discussão sobre o papel da matemática e a natureza dos modelos matemáticos no meio social. Segundo os autores, utilizar a perspectiva sociocrítica da modelagem permite que a Matemática seja vista como uma disciplina humana e dinâmica. Para eles, a dimensão sociocrítica da modelagem envolve a compreensão e o entendimento da realidade em que estudantes estão inseridos por meio de reflexão, análise e ação crítica sobre essa realidade, não sendo a Matemática e os modelos um fim neles mesmos.

O Quadro 2, a seguir, sintetiza as possibilidades na dimensão estrutural descritas no estudo de Prado et al. (2016). Na última linha do quadro, apresentamos duas possibilidades de prática pedagógica: a primeira é sugerida a partir dos textos dos materiais curriculares educativos sobre modelagem matemática (imagem flexibilizadora), e a segunda é uma contraposição teórica em relação a primeira, a qual denominamos de imagem disciplinalizadora.

Neste quadro, apresentamos algumas questões que podem orientar a análise de textos de materiais curriculares. Essas questões foram constituídas a partir de características já postas na literatura sobre modelagem matemática, em especial, as evidenciadas nos trabalhos Silva et al. (2009) e Silva e Kato (2012). 
Quadro 2: Imagens da dimensão estrutural da prática pedagógica em Materiais Curriculares Educativos sobre Modelagem Matemática

\begin{tabular}{|c|c|c|c|}
\hline Relações & $\begin{array}{l}\text { Questões que orientam } \\
\text { a análise }\end{array}$ & $\begin{array}{c}\text { Classificação Forte } \\
\text { Fronteiras demarcadas }\end{array}$ & $\begin{array}{l}\text { Classificação Fraca } \\
\text { Fronteiras esbatidas }\end{array}$ \\
\hline Relações intradisciplinares & $\begin{array}{l}\text { (1) Os problemas e } \\
\text { questões estabelecem } \\
\text { relações entre diferentes } \\
\text { conteúdos matemáticos? } \\
(2) \text { Os conteúdos } \\
\text { matemáticos } \\
\text { relacionados com astão } \\
\text { ideias chaves do } \\
\text { problema? }\end{array}$ & \multirow{3}{*}{$\begin{array}{l}\text { Os discursos são apresentados } \\
\text { de forma totalmente isoladas. } \\
\text { Ou em algo que é isolado. }\end{array}$} & \multirow{3}{*}{$\begin{array}{l}\text { Os discursos } r \\
\text { apresentados de } \\
\text { integrada. }\end{array}$} \\
\hline Relações interdisciplinares & 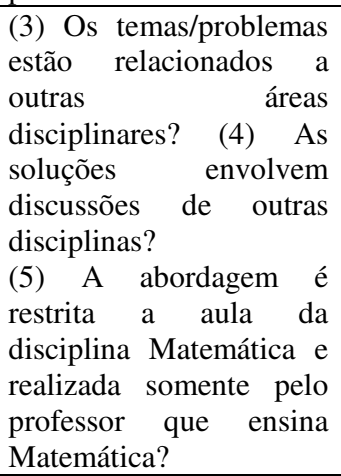 & & \\
\hline 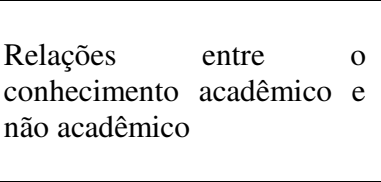 & $\begin{array}{l}\text { (6) Existe relação entre o } \\
\text { conteúdo acadêmico e } \\
\text { não acadêmico? (7) } \\
\text { Ambos são valorizados } \\
\text { nas soluções? }\end{array}$ & & \\
\hline $\begin{array}{l}\text { Relações entre os espaços } \\
\text { dos vários estudantes }\end{array}$ & $\begin{array}{l}\text { (8) Como estudantes são } \\
\text { organizados? Grupo ou } \\
\text { duplas / Individual } \\
\text { (fileiras) / semicírculo. } \\
\text { (9) Todos utilizam os } \\
\text { mesmos materiais? }\end{array}$ & \multirow[b]{2}{*}{$\begin{array}{l}\text { Nítida demarcação entre os } \\
\text { espaços ocupados, assim como } \\
\text { os materiais utilizados por } \\
\text { ambos, bem como, diferentes } \\
\text { estudantes estão claramente } \\
\text { isolados uns dos outros. }\end{array}$} & \multirow{2}{*}{$\begin{array}{l}\text { Esbatimento das fronteiras } \\
\text { entre os espaços } \\
\text { possibilidades } \\
\text { compartilhamento } \\
\text { materiais. } \\
\text { Professores e estudantes, } \\
\text { assim como os diferentes } \\
\text { estudantes ocupam, } \\
\text { indiferentemente, qualquer } \\
\text { espaço da sala de aula, ou } \\
\text { são utilizados da mesma } \\
\text { forma por professores e } \\
\text { estudantes. }\end{array}$} \\
\hline $\begin{array}{l}\text { Relação entre espaços do(a) } \\
\text { professor(a) e espaços dos } \\
\text { estudantes }\end{array}$ & $\begin{array}{l}\text { (10) Há distinção entre } \\
\text { espaços de estudantes e } \\
\text { espaços } \\
\text { professor(a) do(a) } \\
\text { realização da tarefa? (11) } \\
\text { Há distinção entre os } \\
\text { materiais } \\
\text { pelo(a) professor(a) e os } \\
\text { que são utilizados pelos } \\
\text { estudantes? }\end{array}$ & & \\
\hline \multicolumn{2}{|c|}{$\begin{array}{l}\text { Imagem da dimensão estrutural da prática } \\
\text { pedagógica em Materiais curriculares educativos } \\
\text { sobre Modelagem Matemática }\end{array}$} & 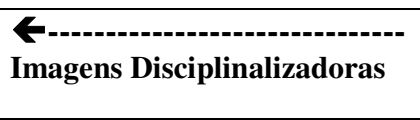 & Imagens Flexibilizadoras \\
\hline
\end{tabular}

Fonte: Os autores

\section{Relação entre materiais curriculares educativos e modelagem matemática}

Nos estudos realizados por Prado et al. (2014, 2016), a prática pedagógica não foi acessada diretamente, uma vez que os autores buscaram indícios dessa prática nos textos dos materiais curriculares educativos. No entanto, dado que o texto é entendido nesses estudos como qualquer representação pedagógica escrita e visual (BERNSTEIN, 1990), uma imagem da prática pedagógica nos textos dos materiais curriculares educativos foi definida como o resultado de um conjunto de representações pedagógicas escritas e visuais que evidenciam as 
relações entre os participantes envolvidos nessa prática, a distribuição/compartilhamento dos espaços utilizados pelos participantes, as relações entre os discursos utilizados, assim como as relações posicionais entre os participantes. De tal modo que, a expressão imagem da prática pedagógica foi utilizada para diferenciar a prática pedagógica (relações entre participantes num contexto, tempo e espaço específico) e a sua imagem (representações escritas e visuais desta relação).

De acordo com Bernstein (2000), as relações sociais são, inicialmente, dominadas pelo princípio de classificação, pois este determina os limites da comunicação, expressando o que é legítimo, ou seja, o que é socialmente aceito em um determinado contexto comunicativo. É esse princípio que orienta a especificidade do contexto comunicativo.

Ao expressar um esbatimento dos limites/partições e das hierarquias entre as categorias (sejam elas discursos ou espaços), as imagens flexibilizadoras dão o tom da prática pedagógica no ambiente de modelagem matemática, sugerindo, por exemplo, que discursos de diferentes disciplinas, assim como discursos externos devem ser integrados nessa prática. Além disso, sustentam que estudantes e professores devem trabalhar juntos, compartilhando diversos espaços e materiais na sala de aula. De fato, tais princípios convergem para as discussões postas na literatura sobre Educação Matemática, os quais reivindicam, por exemplo, que os ambientes investigativos, tais com o de modelagem matemática, podem favorecer o diálogo (SKOVSMOSE, 2000).

No entanto, não necessariamente, a especificidade do ambiente de modelagem matemática pode fazer constituir práticas pedagógicas menos controladas. Por exemplo, Silva et al. (2007) discutiram a resistência de um grupo de estudantes no desenvolvimento do ambiente de modelagem pela primeira vez. Os estudantes resistiram ao processo de coleta de informações/dados sobre o problema proposto e os autores argumentaram que eles/elas estavam socializados a participarem de ambientes de aprendizagem, nos quais as informações/dados eram sempre entregues pela professora. Nesse caso, apesar da prática pedagógica ser inicialmente instaurada a partir das especificidades do ambiente de modelagem, houve resistências em modificar os padrões de interação, ou seja, de mudar um padrão em que o controle estava centrado na professora, para um padrão no qual o controle seria compartilhado com estudantes.

Assim, apesar das imagens flexibilizadoras comunicarem o tom do ambiente de modelagem matemática, elas sozinhas não são capazes de representar mudanças nos padrões de interação entre professores e estudantes. Isto significa que apesar de valores fracos de classificação que podem ser veiculados por meio das imagens flexibilizadoras, estudantes e/ou professores podem ser resistentes ou encontrar dificuldades em mudar os padrões de 
interação, mantendo os valores fortes de enquadramento na relação, reproduzindo os mesmos padrões de interação de aulas tradicionais.

Portanto, uma potencialidade do material curricular educativo é que, por meio dele, podemos fornecer sugestões para variações no enquadramento para diferentes regras da dimensão interacional, bem como suas funções, já que uma variação de valores fracos para fortes e vice-versa, pode estar fortemente relacionada com o propósito da prática pedagógica como visto nos estudos de Aguiar e Oliveira (2014, 2016). Ou seja, se o objetivo dos materiais curriculares educativos é oferecer apoio aos professores, isso significa que os materiais podem os apoiar a fazer mudanças de forma gradual, mudando o controle para alguns princípios e mantendo outros, até que professores e estudantes se sintam confortáveis em fazer mudanças mais radicais nas práticas pedagógicas.

Por sua vez, enquanto as imagens flexibilizadoras, no âmbito da dimensão estrutural, podem carregar as especificidades do contexto, as imagens da dimensão interacional da prática pedagógica podem oferecer os pressupostos da relação social entre professores e estudantes relacionados a determinado ambiente de aprendizagem. Isto, por sua vez, pode oferecer um maior grau de apoio aos professores.

Neste sentido, as imagens da dimensão interacional da prática pedagógica podem oferecer os pressupostos da relação social entre professores e estudantes relacionados ao ambiente de modelagem matemática, oferecendo sugestões de como o controle sobre aquela prática pode ser alterado o que, por sua vez, pode oferecer um maior grau de apoio aos professores que não conhecem ou tem pouco contato com práticas pedagógicas no ambiente de modelagem matemática.

Além disso, os materiais curriculares educativos, ao sustentarem por meio das imagens da prática pedagógica uma gama potencial de textos legítimos, criam, como consequência, os textos não legítimos a determinado contexto. Neste sentido, os estudos, tomados neste artigo, sugerem outras duas imagens da prática pedagógica em materiais curriculares educativos. Como apresentamos anteriormente, em direção contrária às imagens de deslocamentos, denominamos de imagens de acumulação aquelas que criam, condicionam e organizam as possibilidades para a manutenção do controle nas relações entre sujeitos. As imagens de acumulação podem ser capazes de sugerir práticas pedagógicas totalmente abertas, nas quais o adquirente participa de todas as escolhas e decisões do processo de aprendizagem; ou, em outro extremo, nas quais o adquirente é totalmente alheio a estas escolhas e decisões. Enquanto que, no primeiro caso, as imagens podem, amplamente, evidenciar as condições necessárias para conduzir um cenário para investigações com referência na realidade (SKOVSMOSE, 2000), no segundo caso, as práticas convergem para os padrões de interações nas práticas pedagógicas consideradas tradicionais. 
Como também foi apresentado, contrária as imagens flexibilizadoras, outra imagem pode ser constituída quando o texto tende a criar e condicionar as possibilidades para a conservação dos limites/partições entre discursos e espaços e geração/manutenção das hierarquias e especializações entre sujeitos. Estas foram denominadas de imagens disciplinalizadoras.

O esquema apresentado em Prado et al. (2014), na Figura 1, a seguir, sugere uma generalização que pode ser útil para pesquisas que têm como objetos de estudo os materiais curriculares educativos. Assim, pode ser usado na análise de textos em materiais curriculares educativos com focos sobre os domínios da prática pedagógica, tanto na dimensão estrutural quanto na dimensão interacional, podendo possibilitar a compreensão sobre como as imagens da prática pedagógica podem ser expressas por meio dos textos.

Modelagem matemática e desenvolvimento de materiais curriculares educativos têm sido ainda um tema pouco explorado, principalmente, no cenário nacional. Pesquisas nessa direção podem ajudar a ampliar a gama de materiais curriculares disponíveis em resposta à pouca presença, já identificado na literatura desse ambiente nos textos de materiais curriculares (SILVA et al., 2009; SIQUEIRA, 2014). Por outro lado, as imagens da prática pedagógica, apresentadas neste artigo, podem ainda ser úteis se adaptadas para análise da própria prática pedagógica, e, por sua vez, subsidiar a formação de professores, ao propor, por exemplo, que professores reflitam e elaborem ambientes de aprendizagem, levando em consideração as duas dimensões da prática pedagógica: a dimensão interacional e a dimensão estrutural. Com isso, professores podem questionar sobre quais mudanças são necessárias nessas dimensões para que possamos alcançar os objetivos de aprendizagem em ambientes de modelagem matemática.

Figura 1: Esquema de análise da prática pedagógica em MCEMM

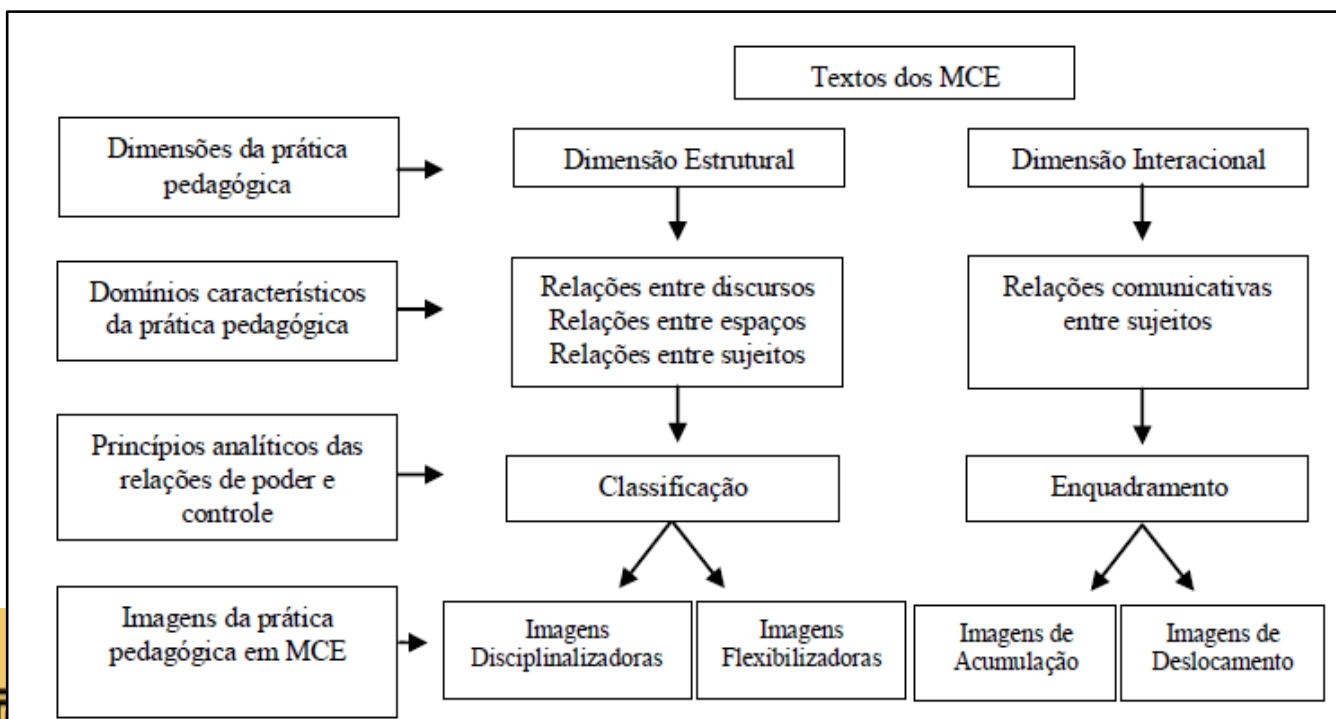


Fonte: Prado et al. (2014)

Assim, é objetivo também deste texto convidar a comunidade de pesquisadores e professores que ensinam Matemática a criticar as discussões postas neste artigo, a fim de que possamos investigar as possibilidades e os desafios de se construir materiais curriculares que possam oferecer maior possibilidade de apoio aos professores. Entretanto, se por um lado, as tarefas de modelagem ou investigações matemáticas de maneira mais global tendem a levar estudantes em territórios menos demarcados, sugerindo um maior grau de autonomia aos estudantes, por outro lado, os(as) professores(as) podem estar equipados com um mapa do território e as rotas típicas dos estudantes para poder acompanhá-los por meio desse território (REMILLARD et al., 2009). Ou seja, os materiais curriculares educativos podem oferecer apoio aos professores no processo de implementação de tarefas que apresentam princípios diferentes dos pressupostos das práticas pedagógicas consideradas tradicionais. Porém, os materiais curriculares educativos, de maneira alguma, podem ser vistos como determinantes das práticas pedagógicas ou alterar práticas pedagógicas por si mesmo, pois é preciso considerar que as relações que se estabelecem nas aulas entre professores e estudantes, ainda carregam um potencial espaço para mudanças, dado que as relações sociais são moldadas e constituídas nos próprios contextos.

\section{Referências}

AGUIAR, W. R.; OLIVEIRA, A. M. P. A Transformação dos Textos dos Materiais Curriculares Educativos por Professores de Matemática: uma análise dos princípios presentes na prática pedagógica. Bolema: Boletim de Educação Matemática, v. 28, p. 580-600, 2014.

AGUIAR, W. R.; OLIVEIRA, A. M. P. Uma análise dos princípios presentes na transformação de materiais curriculares educativos por professores que ensinam Matemática. Ensino \& Pesquisa, v. 14, p. 214-239, 2016.

ALMEIDA, L. M. W; ZANIN, A. P. L. Competências dos alunos em atividades de modelagem matemática. Educação Matemática Pesquisa, v.18, n. 2, p. 759-782, 2016.

BARBOSA, J. C. Mathematical modelling in classroom: a critical and discursive perspective. ZDM - The International Journal on Mathematics Education, v. 38, n. 3, p. 293-301, 2006.

BARBOSA, J. C. Integrando Modelagem Matemática nas práticas pedagógica. Educação Matemática em Revista, v. 26, p. 17-25, 2009.

BERNSTEIN, B. Class, Codes and Control: the structuring of pedagogic discourse. London: Routledge, 1990.

BERNSTEIN, B. Pedagogy, symbolic control and identify: theory, research, critique. Lanham: Rowman \& Littlefield Publishers, 2000. 
BIENBEMGUT, M. S. Modelagem Matemática \& Resolução de Problemas, Projetos e Etnomatemática: Pontos Confluentes. Alexandria: Revista de Educação em Ciência e Tecnologia, v. 7, n. 2, p. 197-219, 2014.

BROWN, M. W. The Teacher-Tool Relationship: Theorizing the Design and Use of Curriculum Materials. In: REMILLARD, J. T.; HERBEL-EISENMANN, B. A.; LLOYD, G. M. (Ed.). Mathematics teachers at work: Connecting Curriculum Materials and Classroom Instruction. New York: Routledge, 2009, p. 17-36.

COLLOPY, R. Curriculum materials as a professional development tool: How a mathematics textbook affected two teachers' learning. Elementary School Journal, Chicago, v. 103, n. 3, p. 287-311, 2003.

DAVIS, E. A.; KRAJCIK, J. S. Designing Educative Curriculum Materials to Promote Teacher Learning. Educational Researcher, v. 34, n. 3, p. 3-14, 2005.

FERNANDES, M. C. S. G; BLENGINI, G.D. Concepções e práticas pedagógicas inovadoras na educação infantil: limites e possibilidades para a transformação. In: ENCONTRO NACIONAL DE DIDÁTICA E PRÁTICAS DE ENSINO, 16., 2012, Campinas. Anais... Campinas: UNICAMP, 2012.

GROSSMAN, P. L.; THOMPSON, C. Curriculum materials: Scaffolds for new teacher learning? Seattle: University of Washington, Center for the Study of Teaching and Policy. 2004.

IKEDA, T. Possibilities for, and obstacles to teaching applications and modelling in the lower secondary levels. In: BLUM, W.; GALBRAITH, P.; HENN, H.; NISS, M. (Ed.). Modelling and Applications in Mathematics Education: the 14th ICMI study, New York: Springer, v. 14, p. 457-462, 2007.

JACOBINI, O. R.; Espaço para Reflexões Políticas e Culturais nas aulas de Matemática. In: ENCONTRO NACIONAL DE EDUCAÇÃO MATEMÁTICA, 9., 2007, Belo Horizonte. Anais... Belo Horizonte: SBEM, 2007.

KAISER, G.; SRIRAMAN, B. A global survey of international perspectives on modelling in mathematics education. ZDM - The International Journal on Mathematics Education, v. 38, n. 3, p. 302-310, 2006.

MORAIS, A. NEVES, I. Processos de intervenção e análise em contextos pedagógicos. Educação, Sociedade e Culturas, v. 19, n. 2, p. 49-87. 2003.

OREY, D. C.; ROSA, M. A dimensão crítica da modelagem matemática: ensinando para a eficiência sociocrítica. Horizontes, v. 25, n. 2, p. 197-206, 2007.

PRADO, A. S. As imagens da prática pedagógica nos textos dos materiais curriculares educativos sobre modelagem matemática. 112f. 2014. Dissertação (Mestrado em Ensino, Filosofia e História das Ciências) - Universidade Federal da Bahia, Salvador, 2014. 
PRADO, A. S; OLIVEIRA, A. M. P; BARBOSA, J. C. Uma análise sobre a imagem da dimensão interacional da prática pedagógica representada em materiais curriculares educativos. Educação Matemática Pesquisa, v. 16, n. 2, p. 505-535, 2014.

PRADO, A. S; OLIVEIRA, A. M. P; BARBOSA, J. C. Uma Análise Sobre a Imagem da Dimensão Estrutural da Prática Pedagógica em Materiais Curriculares Educativos. Bolema: Boletim de Educação Matemática, v. 30, n. 55, p. 738-762, 2016.

REMILLARD, J. T. Examining key concepts in research on teachers' use of mathematics curricula. Review of Educational Research, v. 75, n. 2, p. 211-246, 2005.

REMILLARD, J. T.; HERBEL-EISENMANN, B. A.; LLOYD, G. M. (Ed.). Mathematics teachers at work: Connecting Curriculum Materials and Classroom Instruction. New York: Routledge, 2009.

SILVA, C.; KATO, L. A. Quais Elementos Caracterizam uma Atividade de Modelagem Matemática na Perspectiva Sociocrítica? Bolema: Boletim de Educação Matemática, v. 26, n. 43, p. 817-838, 2012.

SILVA, C.; NOGUEIRA, C. M. I.; KATO, L. A. Possibilidade de trabalho com modelagem matemática em livro didático do ensino médio. In: ENCONTRO PARANAENSE DE EDUCAÇÃO MATEMÁTICA, 10., 2009, Guarapuava. Anais... Guarapuava: Universidade Estadual do Centro-Oeste, 2009.

SILVA, M. S.; SANTANA, T. S.; BARBOSA, J. C. Modelagem Matemática e a resistência de um grupo de alunos. In: CONFERÊNCIA NACIONAL SOBRE MODELAGEM NA EDUCAÇÃO MATEMÁTICA, 5., 2007, Ouro Preto. Anais... Ouro Preto: Universidade Federal de Ouro Preto e Universidade Federal de Minas Gerais, 2007. p. 945-957.

SIQUEIRA, M. A. Modelagem matemática e livro didático no ensino médio: um olhar para o PNLD. 2014. 231f. Dissertação (Mestrado em Educação em Ciências e em Matemática) Universidade Federal do Paraná, Curitiba, 2014.

SKOVSMOSE, O. Cenários para Investigação. Bolema: Boletim de Educação Matemática, n. 14, p. 66-91, 2000.

\section{SOBRE OS AUTORES}

AIRAM DA SILVA PRADO. Possui graduação em Licenciatura em Matemática pela Universidade Estadual de Feira de Santana (2010), Mestre pelo Programa de Pós-Graduação em Ensino, Filosofia e História das Ciências (PPGEFHC) pela Universidade Federal da Bahia e Universidade Estadual de Feira de Santana (2014). Atualmente, é doutoranda pelo mesmo programa PPGEFHC/UFBA/UEFS. Membro do Grupo de Pesquisa Ensino de Ciências e Matemática (ENCIMA) e do Observatório da Educação Matemática (OEM-Bahia). Tem experiência na área de Educação Matemática, com ênfase em Formação de professores que ensinam Matemática, Modelagem Matemática, Prática Pedagógica e Materiais Curriculares Educativos. 
ANDRÉIA MARIA PEREIRA DE OLIVEIRA. Possui graduação em Licenciatura em Matemática pela Universidade Católica do Salvador (1995), Mestrado em Educação Matemática pela Universidade Estadual Paulista Júlio de Mesquita Filho (2003) e Doutorado em Ensino, Filosofia e História das Ciências pela Universidade Federal da Bahia e Universidade Estadual de Feira de Santana (2010). Atualmente, é professora adjunta da Faculdade de Educação da Universidade Federal da Bahia e é credenciada como professora permanente no Programa de Pós-Graduação em Ensino, Filosofia e História das Ciências da UFBA/UEFS e no Programa de Pós-Graduação em Educação da UFBA. Membro do Grupo de Pesquisa Ensino de Ciências e Matemática (ENCIMA) e do Observatório da Educação Matemática (OEM-Bahia). Tem experiência na área de Educação Matemática, com ênfase em Formação e prática pedagógica de professores que ensinam Matemática, Modelagem Matemática e Materiais Curriculares Educativos.

JONEI CERQUEIRA BARBOSA. Possui graduação em Matemática pela Universidade Católica do Salvador (1997), Doutorado em Educação Matemática pela Universidade Estadual Paulista Júlio de Mesquita Filho (2001) e estágio pós-doutoral na London South Bank University (2008-2009) e na University of London (2013-2014). É pesquisador produtividade, nível 2, do CNPq. Atualmente, é professor adjunto da Faculdade de Educação da Universidade Federal da Bahia e é credenciado como professor permanente no Programa de Pós-Graduação em Ensino, Filosofia e História das Ciências da UFBA/UEFS e no Programa de Pós-Graduação em Educação da UFBA. Líder do Grupo de Pesquisa Ensino de Ciências e Matemática (ENCIMA). Tem experiência na área de Educação Matemática, com ênfase em Modelagem Matemática, Materiais Curriculares Educativos e Formação de Professores que ensinam Matemática.

Recebido: 13 de março de 2017.

Revisado: 13 de junho de 2017.

Aceito: 07 de julho de 2017. 